\title{
Exploring motivations to seek and undergo prosthodontic care: an empirical approach using the Theory of Planned Behavior construct
}

This article was published in the following Dove Press journal:

Patient Preference and Adherence

12 September 2014

Number of times this article has been viewed

\author{
Antonio Hélio Vieira \\ Cláudio Rodrigues Leles \\ Department of Prevention and Oral \\ Rehabilitation, School of Dentistry, \\ Federal University of Goias, Goiania, \\ Goias, Brazil
}

\begin{abstract}
Motivations for seeking and undergoing prosthodontic care are poorly understood and are not often explored for clinical purposes when determining treatment need and understanding the factors related to the demand for health care and effective use. This article uses the Theory of Planned Behavior construct to identify factors related to the motivations of edentulous subjects to seek and undergo prosthodontic treatment. The conceptual framework of the Theory of Planned Behavior includes attitude toward behavior, an individual's positive or negative evaluation of self-performance of the particular behavior; the subjective norm, an individual's perception of social normative pressures or relevant others' beliefs that he or she should or should not perform such behavior; and perceived behavioral control, or an individual's perceived ease or difficulty in performing the particular behavior, determined by the total set of accessible control beliefs. These components mediate a subject's intention and behavior toward an object and may also explain health-related behaviors, providing strong predictions across a range of health behaviors. This study suggests categories for each component of the Theory of Planned Behavior, based on clinical evidence and practical reasoning. Attitudes toward behavior include perceived consequences of no treatment, perceived potential benefits and risks of treatment, dental anxiety, previous experiences, and interpersonal abilities of the health care providers. The subjective norm includes the opinions of relevant others, advertisement, professionally defined normative need, perceived professional skills, and technical quality of care. Perceived behavioral control includes subject's time, availability and opportunity, treatment costs, subject's perceived need, and accessibility to dental care. This conceptual model represents a theoretical multidimensional model that may help clinicians better understand the patient's treatment behaviors and provide additional information for clinical research on patient's adherence to interventions in prosthodontics.
\end{abstract}

Keywords: edentulous patient, prosthodontics, health services needs and demand, behavior

\section{Introduction}

Little is known about a patient's motivations in seeking prosthodontic care with the exception of anecdotal information from consumers of dental care services. Internet Web sites advise consumers about minimum requirements, whereas others advise patients on how to recognize and select a good dentist. ${ }^{1}$ Professional dental associations also assist consumers in making an informed choice of dental practitioner ${ }^{2,3}$ but focus mainly on the professionals' point of view, rather than on the patients' perspective. In addition, service provision varies by dentist, practice, and patient factors, including characteristics such as treatment choices, practice beliefs, preferences for patients, and demographic characteristics as well as socioeconomic and geographic barriers on service patterns. ${ }^{4}$

It is generally accepted that dentists may have some attributes they use to capture patients' confidence, such as good technical skills and interpersonal behavior. Indeed, 
issues concerning "professional competence," together with the nature and quality of the patient-professional relationship, are considered key predictors of overall consumer satisfaction with general practice, dental, and hospital care. ${ }^{5}$

However, in addition to the interpersonal relationship and the technical quality of care, other multidimensional components of patient satisfaction, such as certain aspects of delivery of care, must be considered by health care providers, including accessibility and availability of care, costs, outcomes, continuity of care, and the physical environment. ${ }^{6}$ In addition, from a more wide-ranging evaluation of health service quality from public and patients, a conceptual framework from Calnan ${ }^{7}$ also incorporated an individual's goals in seeking health care in each specific instance, the level of experience in using health care, the sociopolitical values on which the particular health care system is based, and the images of health held by the lay population. These are also mediated through sociodemographic characteristics of the service users. ${ }^{7}$

In this context, measuring consumer satisfaction may be important not only as an outcome variable but also as a mediating variable that may influence illness behavior and treatment compliance. ${ }^{5}$ However, instruments that assess patient satisfaction are not designed to predict the likelihood of seeking treatment and other aspects of an individual's health behavior.

A conceptual model of consumers' behavior was proposed in 1980 by Ajzen and Fishbein, ${ }^{8}$ who formulated the
Theory of Reasoned Action, which aimed to assess the discrepancy between attitude and behavior, using a conceptual framework capable of predicting human behavior on the basis of the attitude toward an object. The basic framework of the Theory of Reasoned Action model is that behavior is affected by behavior intention, and behavior intention is affected by the attitudes toward the behavior and subjective norms. ${ }^{8}$ Later, Ajzen ${ }^{9}$ observed that behavior did not appear to be entirely voluntary and under control, leading to the addition of perceived behavioral control. With this addition, the model was called the Theory of Planned Behavior (TPB) and was intended to predict deliberate behavior, stating that humans are rational analyzers of a situation and that one's intention is actually what mediates (comes between) attitude and behavior. ${ }^{9}$ The conceptual framework of the TPB and explanations of its key terms are represented in Figure 1.

TPB was conceived to explain virtually any human behavior and was also used to explain health-related behaviors, providing strong predictions of intention and behavior across a range of health behaviors. ${ }^{10,11}$ TPB has also been used for modeling intention to improve oral health-related behaviors, focusing on oral hygiene habits, ${ }^{12-14}$ but with no emphasis on other treatment demands such as restorative and prosthodontic care.

We hypothesize that TPB can be used for modeling and predicting intentions and behaviors about treatment of edentulous subjects, considering the assumptions that consumers of prosthodontic care are rational, make systematic

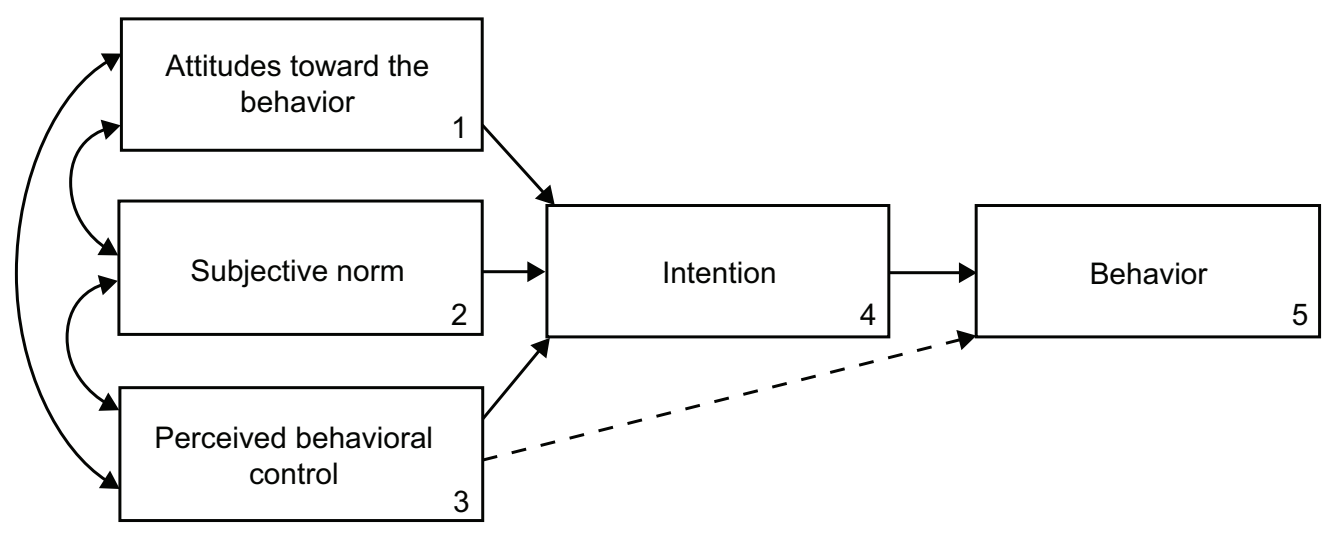

Figure I Conceptual framework of the Theory of Planned Behaviour.

Notes: Adapted from Organizational Behavior and Human Decision Process: Ajzen I. The theory of planned behavior. 1991;50(2):179-2II. Copyright (C) 199I, with permission from Elsevier. ${ }^{9}$ The components of the Theory of Planned Behaviour concept are defined as: (I) Attitudes toward the behavior: an individual's positive or negative evaluation of self-performance of the particular behavior. The concept is the degree to which performance of the behavior is positively or negatively valued. It is determined by the total set of accessible behavioral beliefs linking the behavior to various outcomes and other attributes. The individual's beliefs about the potential results of a particular behavior, based on the subjective probability that the behavior will produce a given outcome. (2) Subjective norm: an individual's perception of social normative pressures, or relevant others' beliefs that he or she should or should not perform such behavior. The individual's perception about the particular behavior, which is influenced by the judgment of significant others (parents, spouse, friends). (3) Perceived behavioral control: an individual's perceived ease or difficulty in performing the particular behavior, determined by the total set of accessible control beliefs. An individual's beliefs about factors that may facilitate or inhibit performance of the behavior. (4) Intention: an indication of an individual's readiness to perform a given behavior based on attitude toward the behavior, subjective norm, and perceived behavioral control, with each predictor weighted for its importance in relation to the behavior and population of interest. (5) Behavior: an individual's observable response in a given situation with respect to a given target. It is considered a function of compatible intentions and perceptions of behavioral control in that perceived behavioral control is expected to moderate the effect of intention on behavior, such that a favorable intention produces the behavior only when perceived behavioral control is strong. 
use of the information available to them, and consider the implications of their actions before they decide about their treatment behaviors. Thus, the aim of this study was to use the TPB framework to propose categorized factors that are related to the willingness to seek and undergo prosthodontic treatment by edentulous individuals, discriminating which factors influence attitudes, subjective norms, and perceived behavioral control that lead to patients' intentions and behaviors about prosthodontic care.

\section{TPB components and prosthodontic care}

Common aspects of patients' treatment-seeking behavior may be identified, considering their potential views, concepts, and attitudes about prosthodontic treatment. We considered that these components may have an influence on an individual's intention to treat and on his/her actual behavior, ranging from seeking treatment to choosing a prosthodontist and being effectively treated.

All the proposed items were gathered, analyzed, and merged into separate categories. In a following step, the categories were allocated into the predictive factors of the TPB conceptual framework (attitude toward behavior, subjective norm, and perceived behavioral control) and are detailed in Table 1. The components of TPB were coded as major dimensions, and the subsequent categories in each component were described as follows.

\section{Attitudes toward behavior}

Attitudes toward behavior constitute an individual's positive or negative evaluation of self-performance of seeking prosthodontic treatment, which may be affected by perceived consequences of treating or not treating, how they are affected by previous positive or negative experiences, and how they are able to cope with fear and other negative feelings. This component was empirically categorized into several major categories.

Perceived consequences of no treatment represent the result of the individual's self-evaluation when faced with a real or hypothetical condition of tooth loss and need for prosthodontic treatment, taking into account the positive and negative consequences of no treatment. ${ }^{15}$ For example, one may wonder whether not restoring lost posterior teeth or not replacing a less-than-ideal removable partial denture can potentially or actually result in some complication in the near- or long-term future. Obviously, favorable or unfavorable arguments regarding treatment may be influenced by other clinical and psychosocial factors that may be considered when deciding to perform the behavior.

Perceived potential benefits and risks of treatment include self-assessment of risks and benefits as part of a context in which the potential patient considers whether favorable factors or positive results are likely to occur after completion of treatment ${ }^{15,16}$ (eg, improved chewing, aesthetics, self-esteem). This category also takes into consideration whether positive aspects overcome the perceived risks involved both with the execution of treatment and with the likelihood of complications and treatment failure in the long-term, such as damage to remaining teeth, risk of surgery and postoperative complications, risk of early treatment failure, worsening of the current condition, and other potential problems. ${ }^{15}$

Table I Theory of Planned Behavior components (attitudes toward behavior, subjective norm, and perceived behavioral control) and categories that represent factors that may influence intention and/or behavior toward prosthodontic treatment

\begin{tabular}{|c|c|c|c|}
\hline Component & Attitudes toward behavior & Subjective norm & Perceived behavioral control \\
\hline Description & $\begin{array}{l}\text { An individual's positive or negative evaluation } \\
\text { of self-performance of seeking prosthodontic } \\
\text { treatment may be influenced by perceived } \\
\text { consequences of treating or not treating, } \\
\text { how they are affected by previous positive or } \\
\text { negative experiences, and how they are able } \\
\text { to cope with fear and other negative feelings }\end{array}$ & $\begin{array}{l}\text { An individual's perception of } \\
\text { social normative pressures, such } \\
\text { as opinions of family members } \\
\text { or friends, or recommendations } \\
\text { of the dentist about the need for } \\
\text { prosthodontic treatment. }\end{array}$ & $\begin{array}{l}\text { An individual's beliefs about factors } \\
\text { that may facilitate or make difficult } \\
\text { seeking treatment may include factors } \\
\text { related to the availability of time to } \\
\text { perform treatment and whether it } \\
\text { is convenient at that time or can be } \\
\text { postponed, whether treatment costs are } \\
\text { manageable at present or in the future, } \\
\text { and whether treatment is perceived by } \\
\text { the individual as definitely needed or if } \\
\text { there are neglected oral needs }\end{array}$ \\
\hline Categories & $\begin{array}{l}\text { - Perceived consequences of no treatment } \\
\text { - Perception of potential benefits of treatment } \\
\text { - Perception of potential risks of treatment } \\
\text { - Dental anxiety } \\
\text { - Previous experiences } \\
\text { - Interpersonal interaction }\end{array}$ & $\begin{array}{l}\text { - Opinion of others } \\
\text { - Advertisement } \\
\text { - Normative need } \\
\text { - Professional skills } \\
\text { - Overall quality of care }\end{array}$ & $\begin{array}{l}\text { - Time availability/opportunity } \\
\text { - Costs } \\
\text { - Subject's perceived need } \\
\text { - Accessibility }\end{array}$ \\
\hline
\end{tabular}


Dental anxiety is an emotional state that precedes an encounter for dental treatment, ${ }^{17}$ which may be associated with prior experiences of the person or of other people. It is estimated that between $6 \%-15 \%$ of the population avoids regular dental care because of dental anxiety or phobia. ${ }^{18,19}$ The majority of patients have some degree of anxiety about dental treatment. At perhaps the most basic level, dental anxiety varies across a continuum, from very mild anxiety to severe and debilitating dental phobia that might preclude a person from visiting a dentist even when they are in severe pain or discomfort. ${ }^{20}$ The individual's self-efficacy toward anxiety about dental treatment has a major effect on treatment adherence, ${ }^{10}$ as does an attitude on the part of the professional for a general anxiety-reducing treatment style, by establishing trust and providing realistic information regarding the dental treatment. ${ }^{18}$

Previous experiences, including previous traumatic, difficult, or painful dental experiences, sometimes as a result of an uncaring dentist, can lead to excessive or unreasonable negative attitudes, as direct experience is the most common way people develop dental anxiety. However, observational learning also occurs as a function of observing, retaining, and replicating behavior executed by others, commonly developed as people hear about others' traumatic experiences or negative views of dentistry in our society. Conversely, previous positive experiences may also affect an individual's beliefs and treatment behaviors. Interpersonal comparisons are considered an important aspect of the patient's antecedent perception and attitude concerning treatment, consisting of an individual's rating of the health care encounter by comparing it with all such encounters known to or experienced by him or her. ${ }^{21}$

Interpersonal abilities of the health care providers include the affective component of the dentist; the dental team's attitude toward the patient plays a major role in adherence to treatment and a satisfactory dentist-patient relationship. It has been reported that prosthodontists who communicate better with their patients increase their satisfaction and improve both adherence to dental treatment and the overcoming of previous distressing experiences. ${ }^{22,23}$ Patients also often talk to people they know about their dentists to find one with whom they feel comfortable. In addition to professional expertise, the nature of the interpersonal relationship and the way in which providers interact with patients, demonstrating interpersonal skills such as respect, concern, empathy, friendliness, courtesy, and emotional support, are regarded as the principal components of a patient's satisfaction. ${ }^{7}$ When a satisfactory level of confidence between patient and professional is achieved, continuity of care (ie, constancy in provider and/or location of care) is highly desirable when they are cooperatively involved in ongoing health care management toward the goal of high-quality, cost-effective medical care. ${ }^{6,7,24}$ Continuity of care based on a long-term patient-prosthodontist partnership also optimizes a patient's history from experience and integrates new information and decisions more efficiently without extensive investigation or record review.

\section{Subjective norm}

The subjective norm refers to how an individual perceives and deals with compelling attitudes from family, friends, and relevant others, as well as direct marketing and professional advice about treatment need. It is also determined by the pressure or power of influence of sociocultural values to which the subjects are exposed, depending on their vulnerability.., 10 Four categories were itemized, as follows:

"Opinions of others" refers to the perception of what other people think we should do with respect to a certain behavior. Relevant others are usually the partner, children, other family, friends, colleagues, and other health providers. In prosthodontics, this may include the opinions of relevant others about the subject's oral health status (pleasant or unpleasant), reported experiences with treatment modalities (eg, implant treatment), or experiences with a certain prosthodontist or oral care service. In the general market, outside influences of other individuals (mainly others who may be important to us) persuade the consumer's opinion of a product or service. The influence over the subject's decisions may vary according to the relative importance given to the opinion of others, as well as to the degree of reliance on the informant. Information on the influence of these relevant others is an important aspect for the prosthodontist to consider when involving patients in treatment decisions and preferences about treatment options.

Advertisements include the use of advertising media or other communication strategies to reach potential customers. Their power of influence is related to the quality of the communication and the subject's susceptibility to the information received. However, advertisements for health care products and services must follow a variety of special advertising laws, regulations, and enforcement agency guidelines.

A normative need is a need identified according to a norm or set standard. These standard requirements are set by professional experts and may play significant roles in the assessment of prosthodontic needs. In prosthodontics, normative needs are usually diagnosed on the basis of the potential harmful aspects of tooth loss, including limited 
functioning, occlusal instability, risk for temporomandibular disorders, and aesthetic effect. Dentists in general focus on the physical functioning of the teeth, whereas patients focus on social meanings of the mouth, resulting in differing priorities in treatment decisions. ${ }^{25}$ Further research on the relationship between denture use and social identity could be beneficial. Normative needs are frequently overestimated when compared with other strategies that consider individual propensities, effects on oral health-related quality of life, and overall societal implications. ${ }^{26-28}$ Hence, factors such as risk for overtreatment at the individual level and overdimensioned dental workforce planning at the societal and economic levels may occur.

Professional skills and quality of care are important aspects of the health care delivered, which is assessed in terms of technical competence of providers and adherence to high standards of diagnosis and treatment. ${ }^{6}$ The technical ability of the health professional is usually thought of by health care workers as the most important component of care and, obviously, an important aspect for the patient's overall perception of quality of health care. However, it is thought that patients often assume a basic level of technical competence from their doctors, and it is not clear on what basis a lay person is able to assess a professional's technical skills or the quality of technical aspects of care. ${ }^{6,24}$ Hence, patients' perceptions of professional's ability are largely determined by their perceptions of the interpersonal qualities of the health provider. ${ }^{29}$ If the interpersonal skills are limited, then technical skills may not be considered by the patient. ${ }^{24}$

\section{Perceived behavioral control}

Perceived behavioral control refers to an individual's perception of the resources and opportunities available to that person, which must to some extent dictate the likelihood of behavioral achievement. ${ }^{10}$ This suggests why some people feel a necessity to seek prosthodontic dental care while others are lifelong irregular users, and still others discontinue regular use after retirement or relocation to a new community or long-term care facility. ${ }^{30}$

Time availability and opportunity consider the time the subject has available or accessible to dedicate to treatment. The time factor can also refer to the duration of time necessary for completion of the dental treatment, as many prosthodontic interventions are extensive and very timeconsuming. In modern society, because of the typical lifestyle found in urban centers, people are inclined to spend less and less time taking care of their personal needs, including health problems, which are frequently postponed down the list of an individual's priorities. Delay in scheduling appointments has also been reported as a major reason for distress in dental care. ${ }^{5}$

"Cost" refers primarily to the monetary value that the patient will have to spend for receiving a prosthodontic treatment. For the patient, it includes initial treatment cost (direct and indirect) and maintenance costs (scheduled and unscheduled). ${ }^{31}$ Although cost may be considered in the context of any positive outcome of the care provided, it is generally perceived by patients as an expensive treatment, which is one of the most important barriers in accessing oral health care, especially for disadvantaged people in developing countries. Subjects with lower incomes and without dental insurance were more than four times more likely to avoid a dental professional because of cost, and approximately two and a half times more likely to decline recommended dental treatment because of cost. ${ }^{32}$

Perceived (felt) need is the subjects' self-assessed oral condition and their individual judgment, based on their own criteria, about the need or not to receive treatment. There is usually a large disparity between the professional (normative need) and patient (perceived need) assessment about prosthodontic treatment needs, ${ }^{28,33}$ which emphasizes the need to find adequate treatment options and planning that includes patients' preferences in an adequate need definition. ${ }^{34}$ Because subjective need without a normative need is rare, patient's perceived need may be the starting point of a clinical assessment of prosthodontic treatment need.

Accessibility to dental care is associated with barriers and facilitators to prosthodontic treatment and has broad dimensions of access to health care, including the availability of dental care resources, ease in reaching a provider, long wait times for an appointment, financial restrictions, insurance coverage, and other specific circumstances that limit health care use. Financial costs and lack of access have been identified as gatekeeping barriers between need-demand and demand-use of prosthodontic treatment. ${ }^{35}$

\section{Conclusion}

This theoretical study was intended to identify factors that influence edentulous subjects' treatment-seeking behavior, which may explain why individuals have different behaviors when dealing with tooth loss or any prosthodontic needs. Discrimination and development of a conceptual structure to adjust TPB domains are essential parts of its use in predicting intention and behavior about prosthodontic treatment.

Research on the influence of positive and negative motivational factors in the formation of intention and behavior 
of subjects has been important for explaining why some people who have strong intentions to achieve a goal succeed while others fail, or why some people continue seeking prosthodontic care throughout their lives while others are lifelong irregular users. ${ }^{30}$ This is important to help decision makers of health services in developing programs and health policies more suitable to the target public, which will in turn enable greater adherence. It also contributes to a better understanding of the psychosocial determinants of health behavior.

Although no previous studies have investigated the use of the TPB in this field, general reviews of the predictive power of this theory on other behaviors, when well-designed studies are elaborated, indicate that the TPB can be an important instrument to explain behavior-related intention and behavior. ${ }^{11,36}$ However, limitations exist in the TPB structure; for example, the temporal distance between the event of interest or measurement of intention and observation of behavior, as well as changes in environmental or economic factors, may influence a person's intention to perform a behavior.

In conclusion, the conceptual framework developed in this study represents a theoretical multidimensional model developed to represent a likely scenario of constant change and is full of specific individual issues. Thus, it is very likely that the conceptual model developed in this study presents inconsistencies and requires adjustments in its formulation. For this reason, it is necessary to conduct studies to test its validity in the population of interest.

\section{Disclosure}

The authors report no conflicts of interest in this work.

\section{References}

1. Barrett S, Baratz RS. How to choose a dentist. Available from: http:// www.quackwatch.org/04ConsumerEducation/dentalchoose.html. Accessed February 14, 2014.

2. American Dental Association. Professional dental associations also assist consumers in making an informed choice of a dental practitioner. http:// www.ada.org/2620.aspx. Accessed December 19, 2013.

3. British Health Foundation. Oral treatments and dental health. Available from: http://www.dentalhealth.org/tell-me-about. Accessed August 22, 2014.

4. Brennan DS, Spencer AJ. The role of dentist, practice and patient factors in the provision of dental services. Community Dent Oral Epidemiol. 2005;33(3):181-195.

5. Williams SJ, Calnan M. Convergence and divergence: assessing criteria of consumer satisfaction across general practice, dental and hospital care settings. Soc Sci Med. 1991;33(6):707-716.

6. Sitzia J, Wood N. Patient satisfaction: a review of issues and concepts. Soc Sci Med. 1997;45(12):1829-1843.

7. Calnan M. Towards a conceptual framework of lay evaluation of health care. Soc Sci Med. 1988;27(9):927-933.
8. Ajzen I, Fishbein M. Understanding attitudes and predicting social behaviour. Englewood Cliffs, NJ: Prentice Hall; 1980.

9. Ajzen I. The theory of planned behavior. Organ Behav Hum Decis Process. 1991;50(2):179-211.

10. Godin G, Kok G. The theory of planned behavior: a review of its applications to health-related behaviors. Am J Health Promot. 1996;11(2): 87-98.

11. McEachan R, Conner M, Taylor NJ, Lawton RJ. Prospective prediction of health-related behaviours with the Theory of Planned Behaviour: a meta-analysis. Health Psychol Rev. 2011;5(2):97-144.

12. Buunk-Werkhoven YA, Dijkstra A, van der Schans CP. Determinants of oral hygiene behavior: a study based on the theory of planned behavior. Community Dent Oral Epidemiol. 2011;39(3):250-259.

13. Dumitrescu AL, Wagle M, Dogaru BC, Manolescu B. Modeling the theory of planned behavior for intention to improve oral health behaviors: the impact of attitudes, knowledge, and current behavior. J Oral Sci. 2011;53(3):369-377.

14. Dumitrescu AL, Duţă C, Dogaru CB, Manolescu B. Predicting undergraduates' intentions to improve oral health behaviors: the importance of self-identity - a pilot study. J Dent Hyg. 2013;87(4):224-234.

15. Leles CR, Martins RR, Silva ET, Nunes MF. Discriminant analysis of patients' reasons for choosing or refusing treatments for partial edentulism. J Oral Rehabil. 2009;36(12):909-915.

16. Silva ME, Magalhães CS, Ferreira EF. [Dental loss and prosthetic replacement expectation: qualitative study]. Cien Saude Colet. 2010; 15(3):813-820. Portuguese.

17. Armfield JM, Heaton LJ. Management of fear and anxiety in the dental clinic: a review. Aust Dent J. 2013;58(4):390-407.

18. De Jongh A, Adair P, Meijerink-Anderson M. Clinical management of dental anxiety: what works for whom? Int Dent J. 2005;55(2):73-80.

19. Tickle M, Jones C, Buchannan K, Milsom KM, Blinkhorn AS, Humphris GM. A prospective study of dental anxiety in a cohort of children followed from 5 to 9 years of age. Int J Paediatr Dent. 2009;19(4): 225-232.

20. Oosterink FM, de Jongh A, Aartman IH. Negative events and their potential risk of precipitating pathological forms of dental anxiety. J Anxiety Disord. 2009;23(4):451-457.

21. Linder-Pelz SU. Toward a theory of patient satisfaction. Soc Sci Med. 1982;16(5):577-582.

22. Hannah A, Millichamp CJ, Ayers KM. A communication skills course for undergraduate dental students. J Dent Educ. 2004;68(9):970-977.

23. Hottel TL, Hardigan PC. Improvement in the interpersonal communication skills of dental students. J Dent Educ. 2005;69(2):281-284.

24. Chow A, Mayer EK, Darzi AW, Athanasiou T. Patient-reported outcome measures: the importance of patient satisfaction in surgery. Surgery. 2009;146(3):435-443.

25. Graham R, Mihaylov S, Jepson N, Allen PF, Bond S. Determining "need" for a Removable Partial Denture: a qualitative study of factors that influence dentist provision and patient use. Br Dent J. 2006;200(3): $155-158$.

26. Srisilapanan P, Sheiham A. Assessing the difference between sociodental and normative approaches to assessing prosthetic dental treatment needs in dentate older people. Gerodontology. 2001;18(1):25-34.

27. Srisilapanan P, Korwanich N, Sheiham A. Assessing prosthodontic dental treatment needs in older adults in Thailand: normative vs sociodental approaches. Spec Care Dentist. 2003;23(4):131-134.

28. Ryu JI, Tsakos G, Sheiham A. Differences in prosthodontic treatment needs assessments between the standard normative and sociodental approach. Int J Prosthodont. 2008;21(5):425-432.

29. Ben-Sira Z. The function of the professional's affective behavior in client satisfaction: a revised approach to social interaction theory. J Health Soc Behav. 1976;17(1):3-11.

30. Kiyak HA, Reichmuth M. Barriers to and enablers of older adults' use of dental services. J Dent Educ. 2005;69(9):975-986.

31. Bassi F, Carr AB, Chang TL, et al. Economic outcomes in prosthodontics. Int J Prosthodont. 2013;26(5):465-469. 
32. Thompson B, Cooney P, Lawrence H, Ravaghi V, Quiñonez C. Cost as a barrier to accessing dental care: findings from a Canadian populationbased study. J Public Health Dent. Epub 2014 Jan 15.

33. Walter MH, Wolf BH, Rieger C, Boening KW. Prosthetic treatment need in a representative German sample. J Oral Rehabil. 2001;28(8): 708-716.

34. Narby B, Kronström M, Söderfeldt B, Palmqvist S. Prosthodontics and the patient: what is oral rehabilitation need? Conceptual analysis of need and demand for prosthodontic treatment. Part 1: a conceptual analysis. Int J Prosthodont. 2005;18(1):75-79.
35. Narby B, Kronström M, Söderfeldt B, Palmqvist S. Prosthodontics and the patient. Part 2: Need becoming demand, demand becoming utilization. Int J Prosthodont. 2007;20(2):183-189.

36. Ajzen I. The theory of planned behaviour: reactions and reflections. Psychol Health. 2011;26(9):1113-1127.

\section{Publish your work in this journal}

Patient Preference and Adherence is an international, peer-reviewed, open access journal that focuses on the growing importance of patient preference and adherence throughout the therapeutic continuum. Patient satisfaction, acceptability, quality of life, compliance, persistence and their role in developing new therapeutic modalities and compounds to optimize clinical outcomes for existing disease states are major areas of interest for the journal. This journal has been accepted for indexing on PubMed Central. The manuscript management system is completely online and includes a very quick and fair peer-review system, which is all easy to use. Visit http://www. dovepress.com/testimonials.php to read real quotes from published authors.

\footnotetext{
Submit your manuscript here: http://www.dovepress.com/patient-preference-and-adherence-journal
} 